\title{
Mulheres gaúchas em tempos de competição eleitoral: o perfil das prefeitas eleitas em 2016
}

\author{
Luciana Scherer ${ }^{1}$ \\ Louise de Lira Roedel Botelho
}

\begin{abstract}
Resumo: Ao longo dos tempos, as mulheres têm passado por mudanças quanto ao seu papel na sociedade. A entrada da mulher no mercado de trabalho permite novas configurações de liderança e de exercício de poder, emergindo situações em que elas passaram a ocupar cargos e funções até então desempenhadas exclusivamente por homens. A evolução dos modelos gerenciais públicos tem permitido que um número cada vez maior de mulheres ocupe espaço na política e na administração pública. No entanto, chama a atenção que, embora o número de mulheres atuantes na política tenha aumentado ao longo dos últimos anos, esse número ainda é sub-representado, se comparado ao número de homens. O objetivo principal deste trabalho é buscar alguns elementos epistemológicos sobre o sistema eleitoral brasileiro e sobre as questões de gênero na política. Como objeto concreto, apresenta-se o número de prefeitas e o respectivo perfil dessas mulheres eleitas no último pleito, em 2016, para atuarem nas gestões municipais entre os anos de 2017 e 2020. A partir das investigações, contata-se que o Rio Grande do Sul elegeu, em 2016, 31 prefeitas dentre os 497 municípios gaúchos, número este que caracteriza a sub-representação feminina no comando das administrações públicas municipais.
\end{abstract}

Palavras-chave: Prefeitas. Mulheres. Administração Pública. Sistema Eleitoral Brasileiro.

Abstract: Throughout the ages women have undergone changes in their role in society. The entry of women into the labor market allows new configurations of leadership and power, emerging situations in which they have occupied positions and functions previously performed exclusively by men. The evolution of public management models has allowed an increasing number of women to occupy spaces in politics and public administration. However, it draws attention that although the number of women acting in politics tends to increase over the past few years it is still under-represented compared to the number of men. The main objective of this work is to find some epistemological elements about the Brazilian electoral system and about gender issues in politics. As concrete object, the number of prefects and the respective profile of these women elected in the last election in 2016 are presented to act in the municipal administrations between the years 2017 and 2020. Based on the investigations, Rio Grande do Sul elected, in 2016, 31 prefects among the 497 Gaucho municipalities, which is the number one female under the command of municipal public administrations.

Keywords: Mayoresses. Women. Public administration. Brazilian Electoral System.

\section{Introdução}

A trajetória da mulher na sociedade está cercada por diferentes transformações. Essas transformações geraram resultados no modo de vida feminino, sendo reflexos das

\footnotetext{
${ }^{1}$ Doutoranda em Desenvolvimento Regional (UNIJUÍ), Mestre em Ciências Sociais (PUCRS), Administradora (UFRGS). Professora no curso de Administração da Universidade Regional Integrada do Alto Uruguai e das Missões. lucianascherer@yahoo.com.br

2 Pós-Doutora em Engenharia e Gestão do Conhecimento (UGSC). Doutora e Mestre no mesmo programa. Administradora (UNIVALI). Professora no curso de Administração e no Mestrado em Desenvolvimento e Políticas Públicas da Universidade Federal da Fronteira Sul. louisebotelho@gmail.com
} 
construções sociais produzidas ao longo dos tempos. A sociedade, talvez para garantir a própria sobrevivência da espécie humana, agregou à mulher o espaço e o papel de cuidadora no ambiente familiar, função social esta que esteve associada por muito tempo à função materna. À medida que a sociedade vai se transformando de uma era agrária para industrial, a função social da mulher vai se adequando aos novos modelos. Surge a emancipação feminina, ou seja, uma busca pela igualdade de gêneros nas relações da esfera do trabalho, e esse novo contexto acaba por modificar as formas como homens e mulheres condicionam suas competências a serviço da sociedade. A partir disso, as mulheres passaram a pertencer à esfera pública do trabalho (FLETCHER, 2006). Como resultado, elas adquiriram direitos e autonomia financeira, que as engendraram no mundo formal do trabalho, e as questões de gênero encontraram dimensão, difundindo-se por vários campos das Ciências Sociais, subsidiando, assim, as evidências culturais do trânsito de homens e mulheres e indicando que as relações sociais de gênero são relações de poder. Um dos campos de estudo neste assunto é a presença das mulheres na política, uma área que durante muito tempo foi percebida legítima, cultural e socialmente como um universo de predomínio masculino.

Com a entrada da mulher no mercado de trabalho, configuram-se também novas lideranças e novas formas de liderar. Elas passaram a ocupar cargos e funções até então desempenhadas exclusivamente por homens (CUNHA; SPANHOL, 2014), trazendo um novo dinamismo às organizações públicas (SOUZA; SIQUEIRA; BINOTTO, 2011).

Durante grande parte da História do Brasil, as mulheres não tiveram participação na política, pois a elas eram negados os principais direitos políticos, como, por exemplo, votar e se candidatar. Porém, hoje, um desses novos papéis, cargos e funções em que as mulheres passam a atuar é o de prefeita. Essa atuação teve início no Brasil com uma primeira mulher eleita em 1929, com a eleição de Alzira Soriano para a prefeitura de Lages, no Rio Grande do Norte, época em que as mulheres sequer tinham o direito de votar, já que esse direito foi conquistado no ano de 1932. Mediante o voto direto, a primeira mulher a ser eleita prefeita no Brasil foi Aldamira Guedes Fernandes, em 1958, no município de Quixeramobim, no Ceará. 
Ao longo desse período, as mulheres empenharam-se para aumentar a sua participação, que continua sub-representada, se comparada ao número de homens que exercem cargos políticos, podendo afirmar-se que o cenário político brasileiro ainda é marcado por traços de tradicionalismo masculino. Referente à atuação em cargos políticos, segundo os dados do Tribunal Superior Eleitoral - TSE (2017)-, embora as mulheres representem cerca de $52 \%$ do eleitorado brasileiro, esta mesma proporção não é retratada na ocupação dos cargos políticos, já que apenas $11 \%$ do total de municípios brasileiros elegeram, em 2016, para a gestão 2017-2020, mulheres para estarem à frente das respectivas prefeituras, ou seja, 637 prefeitas - número menor que o apresentado na eleição de 2012 para a gestão 2013-2016, na qual foram eleitas 664 mulheres em todo o país (TSE, 2017).

No Rio Grande do Sul, repete-se esse decréscimo, com o fato de terem sido eleitas, em 2012, para a gestão 2013-2016, 35 prefeitas, e, em 2016, para a gestão 2017-2020, 31 prefeitas. Estudar as realidades que cercam o fenômeno das mulheres ocupando cargos públicos de gestão e de poder, nos mais variados níveis, configura-se como algo desafiador e necessário para a compreensão do próprio papel social que a mulher desempenha na atualidade. Ao se buscar dados sobre a eleição de mulheres, os perfis de prefeitas ou vereadoras, em especial no Rio Grande do Sul, as informações são parcas e dispersas, o que demonstra certa lacuna de produção de conhecimento sobre o tema em questão e que vem justificar a relevância deste estudo.

O objetivo principal deste trabalho é realizar algumas investigações descritivas acerca do perfil das prefeitas gaúchas eleitas em 2016 para o mandato 2017 - 2020, buscando dados como idade, profissão, estado civil, escolaridade, partidos políticos que representam, perfil populacional dos municípios que as elegeram e região a que pertencem esses municípios, bem como as prefeitas que conquistaram a reeleição, além dos percentuais de votos alcançados.

Quanto ao processo metodológico da pesquisa, esta foi estruturada com base em uma perspectiva descritiva, com postura epistemológica de busca de informações apresentadas em estudos e teorias já existentes sobre o tema, aliada à busca de dados nos sítios do Tribunal Superior Eleitoral - TSE (2017), Tribunal Regional Eleitoral do Rio Grande do Sul - TRE-RS (2017) e da Fundação de Economia e Estatística do Rio Grande do Sul (FEE, 2017). 
Este estudo está divido em três partes, além desta introdução e das considerações finais. A primeira apresenta os delineamentos teóricos acerca do sistema eleitoral brasileiro e as suas nuances sobre questões de gênero. A segunda traz as discussões teóricoepistemológicas sobre a mulher, sua (sub) representação política e o tradicionalismo de gênero no processo eleitoral. Na sequência, são apresentadas as prefeitas gaúchas, com dados sobre seus perfis e dos municípios que serão comandados por elas na gestão 2017 - 2020.

Salienta-se que o presente estudo não pretende evidenciar a realidade das mulheres na política, tampouco abordará o processo de ascensão das mulheres nesse setor, e, sim, concentrar-se em compreender o perfil das prefeitas e dos municípios por elas geridos nesse mandato eletivo, contribuindo assim para um conhecimento sistematizado acerca dessas mulheres que optaram pela carreira política em seus municípios.

\section{Sistema eleitoral brasileiro e questões de gênero}

O sistema eleitoral é a maneira como o Estado define e organiza os critérios segundo os quais os eleitores irão escolher seus representantes por meio de votos, com a finalidade de convertê-los em mandatos para o Poder Executivo e para o Poder Legislativo. Este sistema deve ser amplamente conhecido, e, para isso, o Estado estabelece, na sua Constituição, as formas e os requisitos exigidos para se candidatar e assumir cargos públicos eletivos. 0 sistema escolhido traduz a maneira de considerar e validar as escolhas dos eleitores para cada tipo de cargo político. Com base nisso, a Constituição Federal instituiu que as nossas eleições são regidas pelos sistemas eleitorais majoritário e proporcional, modo de divisão do sistema eleitoral brasileiro.

O sistema majoritário fundamenta-se no princípio da representação da maioria em cada circunscrição eleitoral, sem excluir as minorias (GOMES, 2014), considerando-se vitorioso o candidato que obtiver a maioria dos votos válidos, excluindo-se os brancos e os nulos. Os cargos que são escolhidos nesse sistema eleitoral majoritário são os de Presidente e VicePresidente da República, Governador e Vice-Governador de Estado, Prefeito e Vice-Prefeito, e Senador e respectivos dois suplentes. 
Tal sistema está ainda dividido em sistema majoritário de maioria simples ou de maioria absoluta. O primeiro, com turno único, é estabelecido para prefeito e vice-prefeito em municípios de até 200.000 eleitores, também para a eleição de senador e seus dois suplentes, sendo considerado eleito o candidato que obtiver a maioria dos votos válidos. O segundo, de maioria absoluta, estabelecido para a escolha de governadores e vice-governadores, e também para prefeitos e vice-prefeitos de municípios com mais de 200.000 eleitores, consiste na realização de 10 e 2 o turnos. É considerado vencedor o candidato que obtiver a maioria absoluta dos votos válidos, excluindo os brancos e nulos, ou seja, mais de $50 \%$ desses votos, sendo que, caso nenhum dos candidatos alcance esta votação, haverá nova eleição em segundo turno, com os dois candidatos mais votados no primeiro turno.

Já o sistema proporcional diz respeito à eleição de membros do Poder Legislativo3: a Câmara dos Deputados, as Assembleias Legislativas, a Câmara Legislativa e as Câmaras de Vereadores ${ }^{4}$. Para esses cargos, adota-se o sistema de listas abertas.

O sistema eleitoral brasileiro e as regras que orientam o processo das eleições em todos os níveis (federal, estadual ou municipal; e ainda no sistema majoritário ou proporcional) certamente afetam diretamente as chances de as mulheres serem ou não eleitas. Sobre as questões de gênero no sistema eleitoral, é possível destacar três principais aspectos importantes que influenciam os resultados das eleições para as mulheres:

- a crença quase atávica sobre a distinção entre papéis masculinos e femininos na sociedade, que acaba influenciando líderes de partidos a privilegiarem candidatos masculinos, e, ainda, o menor interesse por parte das mulheres em participar ativamente das disputas eleitorais;

- o custo e o financiamento de uma campanha, pois, segundo Araújo (2009), as mulheres tendem a obter menos recursos para as campanhas em comparação aos seus pares masculinos;

- a forma de organização do sistema de votação de deputados/as federais, estaduais, distritais e vereadores, em que os eleitores votam diretamente nos candidatos (as) - sistema de lista aberta -, o que requer uma formação prévia de

\footnotetext{
${ }^{3}$ Exceto o Senado

${ }^{4} \mathrm{CF} / 1988$ art. $45,27, \S 1^{\circ}, 32, \S 3^{\circ}$ e 29
} 
capital político, sob pena das candidatas ficarem apenas na figuração de campanha, ou, como consideram Grossi e Miguel (2001), "candidatas de mentirinha", sem real capacidade de disputa eleitoral.

Diante dos fatos colocados, busca-se no Sistema Eleitoral Brasileiro questões de destaque que afetam diretamente as questões de gênero, como a Lei 9100/95, a Lei 9504/97 e a Lei $12.034 / 2009$.

A primeira lei prescrevia a exigência do registro de, no mínimo, 20\% de candidaturas femininas por cada partido ou coligação. No mesmo ano, a então Deputada Federal Marta Suplicy, apoiada por mais 26 deputadas, elaborou o Projeto de Lei 783, que cominou na revogação do art. 92 do Código Eleitoral, aumentando o percentual mínimo para 30\%, fazendo entrar em vigor a segunda lei acima citada (VAZ, 2008).

É importante ressaltar que Lei 9504/97 não estabelece a obrigatoriedade de preenchimento das vagas para mulheres e também não incide ao partido um ônus pelo não preenchimento das cotas, facilitando o lançamento de candidatas sem o real apoio do partido ou com chances significativas. Para Blay (2002), houve pouco debate com a sociedade para implantação da lei, especialmente com o movimento de mulheres, já que não ocorreram debates em plenário, além de serem rejeitadas propostas que criariam melhores condições de competição por parte das mulheres. A rejeição dessas propostas deixou lacunas, não contemplando as reivindicações que poderiam fortalecer as mulheres na competição política. Porém, tornar mais visível a questão da pouca representação política da mulher é um ponto positivo da lei (BRABO, 2003), pois trouxe à tona muitas reflexões, discussões e questionamentos sobre essa não participação e até mesmo exclusão da mulher nas esferas de poder, já que a realidade tende a inverter-se ao longo do tempo: se antes as mulheres eram barradas nas listas partidárias, agora os partidos buscam mulheres para compô-las (PINTO, 2001).

Já a 12.034/2009 inova a anteriormente citada, estabelecendo que cada partido ou coligação preencherá o mínimo de 30\% e o máximo de 70\% com candidaturas de cada sexo, e ainda atua diretamente nas questões de custo de campanha e formação política para as mulheres. Quanto a isto, estabelece como norma a aplicação dos recursos do fundo 
partidário, obrigando os partidos a investirem, no mínimo, 5\% do fundo partidário na criação e manutenção de programas de promoção e difusão da participação política das mulheres.

Embora sejam considerados instrumentos legislativos de afirmação das mulheres na política, não estão livres de críticas. Por ser mais fácil incluir mulheres como candidatas para simplesmente cumprir o que a legislação sobre cotas estabelece - do que tentar promover de fato candidaturas femininas, líderes partidários tendem a simplesmente recrutar mulheres sem capital político, não se preocupando em empoderá-las. Quanto mais os processos partidários forem deixados a cargo dos líderes masculinos, em lugar de serem institucionalizados e democratizados, menos as novas figuras femininas terão chances de se inserir de fato no jogo político. Ainda, segundo estudo realizado pela Secretaria Especial para Mulheres, os partidos políticos brasileiros tendem a discriminar suas candidatas na distribuição interna de dinheiro para campanha eleitoral, já que, em pesquisa sobre as eleições de 2010, evidenciou-se que dos R\$ 102,4 milhões distribuídos em 2010 pelos diretórios nacionais dos quatorze maiores partidos do país, as mulheres receberam apenas $8 \%$ dos recursos, embora representassem 19,7\% das candidaturas (SPM, 2014). Segundo Alves (2007), as leis que versam sobre as cotas femininas ainda não são suficientes para a reversão do quadro da ocupação feminina de cargos políticos, e atesta que, se os partidos continuarem a não dar uma significativa visibilidade às candidaturas femininas, o ritmo para que se alcance a igualdade de gênero nas eleições brasileiras, e, portanto, reverta-se essa sub-representação e tradicionalismo masculino na política, pode levar ainda mais de dois séculos.

\section{Mulher, (sub)representação política e tradicionalismo de gênero no processo eleitoral}

A discussão da representação, ou da sub-representação das mulheres aparece no Brasil e no mundo como uma problemática prioritariamente da Ciência Política, porém, a gestão pública também representa um campo teórico epistemológico e ontológico para essas investigações. A questão é que, apesar da ampliação da atuação feminina em diferentes setores da sociedade, em esferas públicas ou privadas, as mulheres ainda estão muito distantes de ser maioria nas instâncias decisórias do poder público. Segundo Vaz 
(2008), a exclusão da mulher na vida política é um reflexo da exclusão da mulher na sociedade e da ausência de seu reconhecimento como sujeito, baseado em grande medida no predomínio da figura do homem, seja no aspecto social, político ou econômico.

Prestes a completar um século da conquista da primeira mulher ao cargo de prefeita, seguida pela conquista do direito ao voto pela mulher, ainda persiste uma realidade de subrepresentação feminina na política. Esse fato torna-se incontestável ao se apresentarem os números proporcionais entre prefeitos/prefeitas no Brasil, conforme apresentados na tabela 1.

\section{Tabela 1 - Prefeitos e Prefeitas no Brasil}

\begin{tabular}{lcccc}
\hline & $\mathbf{2 0 0 4}$ & $\mathbf{2 0 0 8}$ & $\mathbf{2 0 1 2}^{\mathbf{5}}$ & $\mathbf{2 0 1 6}$ \\
\hline Prefeitos no Brasil & 5144 & 5059 & 4904 & 4931 \\
Prefeitas no Brasil & 418 & 504 & 664 & 637 \\
Prefeitos no RS & 479 & 474 & 462 & 466 \\
Prefeitas no RS & 17 & 22 & 35 & 31 \\
\hline
\end{tabular}

Fonte: Elaboração das autoras, com base em TSE (2017) e IBAM (2017)

A sub-representação feminina nos cargos políticos é vista como uma desconexão da proporção entre o público feminino e o masculino, segundo os dados do Tribunal Superior Eleitoral - TSE (2017), pois, embora as mulheres representassem cerca de $52 \%$ do eleitorado brasileiro em 2016 (TSE, 2017), essa mesma proporção não é retratada na ocupação dos cargos políticos. Assim, entende-se que a forma como as pessoas (homens ou mulheres) escolhem seus representantes não depende somente do reconhecimento de que "mulher votaria em mulher x homem votaria em homem", ou, como atestam Miguel e Biroli (2010), entre o voto e a escolha de gênero, há muitas variações na possibilidade de escolha.

Os olhares teóricos sobre a mulher e a sua sub-representação na política, os quais visam à compreensão sobre essa temática, dividem suas atenções tanto para o fato - a preocupação com a ausência das mulheres nas arenas político-eleitorais -, como para as causas do fenômeno. Alguns estudos fixam-se nos fatores que causam essa ausência ou subrepresentação; outros analisam ações e atitudes das mulheres quando eleitas; e ainda outros dedicam-se a investigar o impacto da ausência feminina nas instâncias políticas na sociedade como um todo. Em comum, independentemente do tipo de estudo, surgem entendimentos de

\footnotetext{
${ }^{5}$ Destaca-se que até 2008 havia 5563 municípios no Brasil e 496 no Rio Grande do Sul. A partir de 2008, há um acréscimo de cinco novos municípios: um no Pará; dois em Santa Catarina; um no Rio Grande do Sul; e um no Mato Grosso do Sul; portanto, a partir das eleições de 2012, há 5568 prefeitos brasileiros e 497 gaúchos.
} 
que esse não é um fenômeno meramente político, mas também social, cultural, histórico e econômico (ARAUJO, 2009; ARAÚJO; BORGES, 2012; MIGUEL; BIROLLI, 2010; SACCHET; SPECK, 2010).

Uma das formas de analisar a sub-representação feminina é ir além da busca da realidade contada em números: quantos homens x quantas mulheres, buscando entender, por meio do conhecimento dos perfis dessas mulheres, seus estilos e formas de atuação, as causas e razões dessa sub-representação, além do desenho institucional estático do quadro sociopolítico em que as mulheres estão inseridas. É possível destacar três eixos explicativos que vão além do desenho institucional, tais como o caráter patriarcal subjacente às instituições políticas liberais; os padrões culturais e de socialização e os constrangimentos estruturais à participação política das mulheres (MIGUEL; BIROLI, 2010).

Para a questão da sub-representação da mulher na política brasileira é possível encontrar explicações e relações no tradicionalismo de gênero nos processos eleitorais. Segundo Lovenduski e Norris (1993), se os líderes partidários são simpáticos à necessidade de promover a igualdade de gênero nas candidaturas para os cargos políticos, é possível que assim o façam. De modo contrário, se os líderes não encontrarem na promoção da mulher uma forma legítima de fazer política, eles podem não a promover ou até mesmo bloquear as oportunidades para que elas se tornem candidatas. Estudos apontam para o fato de que, quando se trata de disputa entre homens para uma candidatura, o que vale é a lógica eleitoral, ou seja, a preferência é para aquele candidato que apresenta a maior chance de eleger-se para o cargo em questão. Esse critério mudaria ao se tratar de uma disputa entre homem x mulher, nesse caso, o critério passa a ser sexista, ou seja, há uma preferência por candidatos homens (GROSSI; MIGUEL, 2001).

Ainda em relação ao tradicionalismo masculino na política, ou à maior ligação do poder à esfera masculina, Grossi e Miguel (2001) apontam que, muitas vezes, o poder tem gênero, ou seja, o poder político é masculino, enquanto a mulheres teriam poderes ligados às esferas privadas, como seus lares e famílias. 


\section{As prefeitas gaúchas eleitas em 2016}

No estado do Rio Grande do Sul, foram eleitas, em 2016, para a gestão 2017-2020, 31 prefeitas dentre os 497 municípios gaúchos. Este universo de prefeitas configura apenas 6,2\% de municípios tendo mulheres à frente das suas gestões públicas. Em 2012, foram eleitas 35 mulheres, o que demonstra, comparando-se as duas últimas gestões, uma queda, pequena, mas significativa, se considerarmos a configuração política de gênero das prefeituras.

Talvez o principal destaque nessa comparação entre a eleição de mulheres em 2012 e em 2016 seja que, embora esse período apresente uma queda, o perfil de municípios demonstra uma pequena alteração: em 2012, as 35 prefeitas eleitas estiveram à frente de municípios de até 80 mil habitantes. Em 2016, o poder das mulheres encontra-se em alguns municípios de porte maior daqueles que elegeram prefeitas em 2012.

Os destaques em termos de população estão para os municípios de Alegrete, Sapiranga, Novo Hamburgo e Pelotas. Estes dois últimos, com uma população de 244.007 e 342.649, respectivamente, elegeram, pela primeira vez em sua história, uma mulher prefeita. Pelotas, na região Sul do Estado, apresentou ainda a peculiaridade de eleger a primeira prefeita de sua história, em primeiro turno, com 59,86\% (TRS-RS, 216).

\section{Gráfico 1 - Perfil Populacional dos Municípios que elegeram prefeitas}

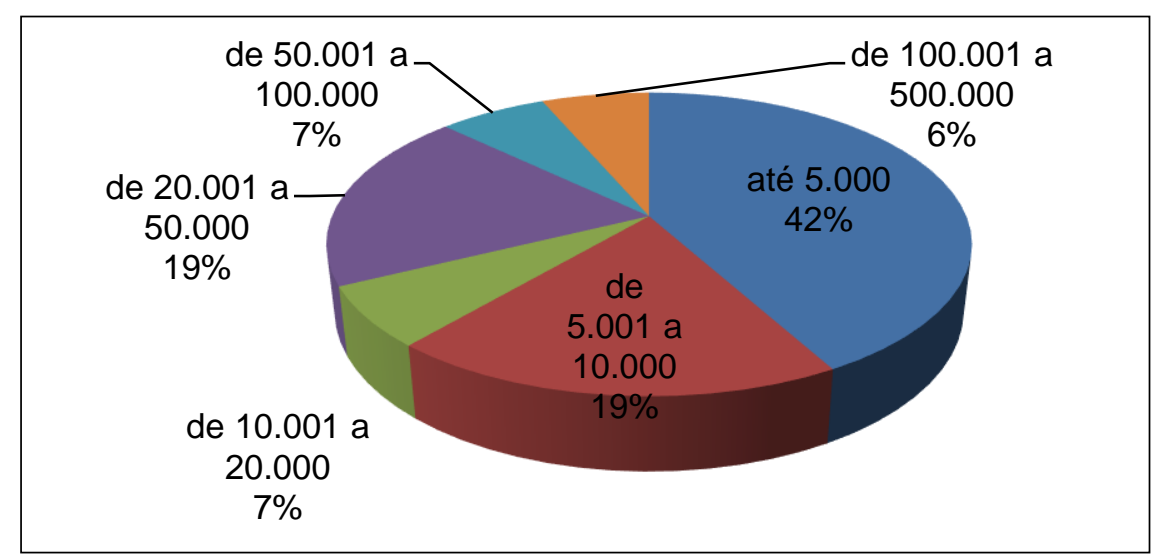

Fonte: Elaboração das autoras, com base nos dados do TRE-RS 
De acordo com os critérios do Instituto Brasileiro de Geografia e Estatística (IBGE, 2010), que classificam os perfis populacionais dos municípios brasileiros ${ }^{6}, 68 \%$ dos municípios gaúchos que elegeram prefeitas são de pequeno porte. Apenas dois municípios (Sapiranga e Alegrete) de médio porte, e ainda dois de grande porte (Novo Hamburgo e Pelotas) elegeram mulheres como chefes do executivo.

Os 31 municípios que elegeram mulheres em 2016 podem ser visualizados na Tabela 2, inserida na próxima página, que também demonstra o perfil populacional e a quantidade de homens e mulheres em cada um.

\footnotetext{
${ }^{6}$ Municípios de Pequeno Porte 1: até 20.000 habitantes; Município de Pequeno Porte 2: de 20.001 até 50.000 habitantes; Município de Médio Porte: de 50.001 até 100.000 habitantes, e Município de Grande Porte: de 100.001 até 900.000 habitantes (IBGE, 2010).
} 
Tabela 2 - Municípios que elegeram mulheres para o cargo de prefeita

\begin{tabular}{|c|c|c|c|c|}
\hline MUNICÍPIO & NOME DA PREFEITA & POPULAÇÃO & HOMENS & MULHERES \\
\hline ALEGRETE & CLENI PAZ & 77.212 & 37989 & 39223 \\
\hline BALNEARIO PINHAL & MARCIA TEDESCO & 12.201 & 6098 & 6103 \\
\hline CAMARGO & ELIANI TRENTIN & 2.729 & 1309 & 1420 \\
\hline CRISTAL & FABIA RICHTER & 7.841 & 3972 & 3869 \\
\hline DOIS IRMÃOS & TANIA T. DA SILVA & 30.354 & 14814 & 15540 \\
\hline DOUTOR RICARDO & CATEA ROLANTE & 1.967 & 1091 & 876 \\
\hline ESTANCIA VELHA & IVETE GRADE & 46.899 & 23485 & 23414 \\
\hline ESTRELA VELHA & CECILIA & 3.526 & 1766 & 1760 \\
\hline FAGUNDES VARELA & CLAUDIA M. TOMÉ & 2.589 & 1284 & 1305 \\
\hline $\begin{array}{c}\text { FORTALEZA DOS } \\
\text { VALOS }\end{array}$ & MARCIA FREDI & 4.619 & 2225 & 2394 \\
\hline IBIAIARAS & IVETE LUCHEZI & 8.214 & 4079 & 4135 \\
\hline ITATIBA DO SUL & ADRIANA TOZZO & 3.715 & 1980 & 1735 \\
\hline IVOTI & MARIA DE LOURDES BAUER & 22.599 & 11224 & 11375 \\
\hline MARAÇARAMBÁ & ADRIANA SCHRAMM & 4.198 & 2205 & 1993 \\
\hline $\begin{array}{l}\text { MAXIMIIANO DE } \\
\text { ALMEIDA }\end{array}$ & DIRLEI B. DOS SANTOS & 4.686 & 2362 & 2324 \\
\hline MORRO REUTER & CARLA CHAMORRO & 6.172 & 3091 & 3081 \\
\hline MUITOS CAPÕES & RITA DE CASSIA PEREIRA & 3.010 & 1630 & 1380 \\
\hline NOVA SANTA RITA & MARGARETE SIMON FERRETI & 25.275 & 12557 & 12718 \\
\hline NOVO HAMBURGO & FATIMA DAUDT & 244.007 & 117277 & 126730 \\
\hline PELOTAS & PAULA MASCARENHAS & 342.649 & 161244 & 181405 \\
\hline QUEVEDOS & NEUSA DOS SANTOS NICKEL & 2.690 & 1448 & 1242 \\
\hline ROSÁRIO DO SUL & ZILASE ROSSIGNOLLO & 40.142 & 19435 & 20707 \\
\hline SANTA CECILIA DO SUL & JUSSARA PERUZZO & 1.698 & 845 & 853 \\
\hline $\begin{array}{l}\text { SANTA MARIA DO } \\
\text { HERVAL }\end{array}$ & MARA SUSANA STOFFEL & 6.693 & 3499 & 3194 \\
\hline SÃO JOSÉ DO NORTE & FABIANY ROGNI ZOIG & 26.191 & 13386 & 12805 \\
\hline $\begin{array}{l}\text { SÃO PAULO DAS } \\
\text { MISSÕES }\end{array}$ & NOILA RUWER & 5.957 & 3004 & 2953 \\
\hline SÃO PEDRO DA SERRA & ISABEL JONER CORNÉLIUS & 3.458 & 1748 & 1710 \\
\hline SAPIRANGA & CORINHA BEATRIZ MOLLING & 78.994 & 39060 & 39934 \\
\hline SERAFINA CORREIA & MARIA AMÉLIA GHELLER & 15.428 & 7729 & 7699 \\
\hline SINIMBU & SANDRA BACKES & 9.867 & 5121 & 4746 \\
\hline TURUÇU & SELMIRA FEHRENBACH & 3.774 & 1836 & 1938 \\
\hline
\end{tabular}

Fonte: Elaboração das autoras, com base nos dados do TRE-RS

Em relação à distribuição político-geográfica dos municípios no estado, buscou-se identificá-la segundo as regiões pertencentes aos 28 Conselhos Regionais de Desenvolvimento (COREDES), e constatou-se que as prefeitas gaúchas estão situadas ao longo de dezessete COREDES. O COREDE Vale do Rio dos Sinos é o que apresenta o maior número de prefeitas. 
Tabela 3 - Municípios comandados por prefeitas nos COREDES

\begin{tabular}{lcl}
\hline \multicolumn{1}{c}{ COREDE } & NÚMERO & \multicolumn{1}{c}{ MUNICIPIOS } \\
\hline VALE DO RIO DOS SINOS & 6 & $\begin{array}{l}\text { Dois Irmãos, Estância Velha, Ivoti, } \\
\text { Nova Santa Rita, Novo Hamburgo, Sapiranga }\end{array}$ \\
\hline FRONTEIRA OESTE & 3 & Alegrete, Maraçarambá, Rosário do Sul \\
\hline NORDESTE & 3 & Ibaiaras, Maximiliano de Almeida, Santa Cecília do Sul \\
\hline SUL & 3 & Pelotas, São José do Norte, Turuçu \\
\hline PARANHANHA ENCOSTA DA SERRA & 2 & Morro Reuter, Santa Maria do Herval \\
\hline SERRA & 2 & Fagundes Varela, Serafina Correia \\
\hline VALE DO RIO PARDO & 2 & Estrela Velha, Sinimbu \\
\hline ALTO JACUI & 1 & Fortaleza dos Valos \\
CAMPOS DE CIMA DA SERRA & 1 & Muitos Capões \\
CENTRAL & 1 & Quevedos \\
CENTRO SUL & 1 & Cristal \\
\hline LITORAL & 1 & Balneário Pinhal \\
MISSÕES & 1 & São Paulo das Missões \\
NORTE & 1 & Itatiba do Sul \\
PRODUÇÃO & 1 & Camargo \\
VALE DO CAÍ & 1 & São Pedro da Serra \\
VALE DO TAQUARI & 1 & Doutor Ricardo \\
\hline
\end{tabular}

Fonte: Elaboração das autoras, com base nos dados do TRE-RS e FEE.

Com base nos dados apresentados na Tabela 3, evidencia-se que, dos 28 , dezessete COREDES possuem municípios representados por prefeitas, sendo que os onze demais - Alto da Serra do Botucaraí, Campanha, Celeiro, Fronteira Noroeste, Hortênsias, Jacuí-Centro, Médio Alto Uruguai, Metropolitano Delta do Jacuí, Noroeste Colonial, Rio da Várzea e Vale do Jaguari não têm nenhuma prefeita nos municípios integrantes.

Em relação aos partidos políticos, oito elegeram mulheres, com destaque para o Partido do Movimento Democrático Brasileiros (PMDB) e para o Partido Progressista (PP). 
Tabela 4 - Partidos políticos das prefeitas

\begin{tabular}{lc}
\hline \multicolumn{1}{c}{ PARTIDO POLÍTICO } & NÚMERO \\
\hline PARTIDO DO MOVIMENTO DEMOCRÁTICO BRASILEIRO - PMDB & 8 \\
PARTIDO PROGRESSISTA - PP & 7 \\
PARTIDO SOCIALISTA BRASILEIRO - PSB & 4 \\
PARTIDO DOS TRABALHADORES - PT & 3 \\
PARTIDO DA SOCIAL DEMOCRACIA BRASILEIRA - PSDB & 3 \\
PARTIDO TRABALHISTA BRASILEIRO - PTB & 3 \\
DEMOCRATAS - DEM & 2 \\
\hline PARTIDO DEMOCRÁTICO TRABALHISTA - PDT & 1 \\
\hline
\end{tabular}

Fonte: Elaboração das autoras, com base nos dados do TRE-RS.

Uma situação bastante importante sobre a atuação de poder das mulheres na política está relacionada à capacidade de reeleição de prefeitas. A reeleição, instituída por emenda constitucional no 16/97, estabelece o direito de chefes do Poder Executivo disputarem a reeleição para a mesma função, para um único mandato e no exercício do cargo. Desde a sua aprovação, já foram realizadas cinco eleições municipais, e os posicionamentos, tanto acadêmicos como políticos, possuem entendimentos contra e a favor de tal prática. Os contrários postulam que a reeleição fere os princípios da alternação do poder e da equidade das condições para a disputa política. Os defensores assumem a ideia de que reeleição pode ser uma forma de aperfeiçoar a capacidade decisória dos eleitores, permitindo punir o mau governante com a não reeleição, ou premiar o bom gestor com um novo mandato, para que continue com suas ações políticas na gestão local. Em 2016, oito prefeitas foram reeleitas, conforme apresentado na Tabela 5. 
Tabela 5 - Municípios que reelegeram suas prefeitas

\begin{tabular}{ll}
\hline MUNICIPIO & PARTIDO \\
\hline CRISTAL & PSB \\
DOIS IRMÃOS & PMDB \\
\hline ITATIBA DO SUL & PT \\
\hline NOVA SANTA RITA & PT \\
ROSARIO DO SUL & PTB \\
\hline SANTA CECÍLIA DO SUL & PSB \\
\hline SÃO PAULO DAS MISSÕES & PMDB \\
\hline SAPIRANGA & PP \\
\hline
\end{tabular}

Fonte: Elaboração das autoras, com base nos dados do TRE-RS

Dos 31 municípios gaúchos que elegeram prefeitas, cinco destacam-se pelo fato de apresentarem apenas mulheres disputando a eleição em 2016: Alegrete, Camargo, Ivoti, Serafina Correa e Estrela Velha (que revela uma situação ainda mais peculiar, já que teve uma única candidata). Em relação aos percentuais de votos que as prefeitas obtiveram em seus municípios, os dados são apresentados na Tabela 6, com esses percentuais em ordem decrescente.

Tabela 6 - Percentuais de votos

\begin{tabular}{llc}
\hline \multicolumn{1}{c}{ MUNICÍPIO } & \multicolumn{1}{c}{ NOME DA PREFEITA } & PERCENTUAL DE VOTOS \\
\hline ESTRELA VELHA & CECILIA MONTAGNER CEOLIN & $100 \%$ \\
\hline MORRO REUTER & CARLA CRISTINE CHAMORRO & $70,81 \%$ \\
\hline SANTA CECILIA DO SUL & JUSSARA PERUZZO & $66,81 \%$ \\
\hline IVOTI & MARIA DE LOURDES BAUER & $66,54 \%$ \\
MARAÇARAMBÁ & ADRIANA SCHRAMM & $65,45 \%$ \\
\hline ROSÁRIO DO SUL & ZILASE ROSSIGNOLLO & $61,88 \%$ \\
BALNEARIO PINHAL & MARCIA TEDESCO & $60,77 \%$ \\
\hline PELOTAS & PAULA MASCARENHAS & $59,86 \%$ \\
SÃO PAULO DAS MISSÕES & NOILA RUWER & $58,80 \%$ \\
\hline ITATIBA DO SUL & ADRIANA KATIA TOZZO & $58,64 \%$ \\
NOVA SANTA RITA & MARGARETE SIMON FERRETI & $57,10 \%$ \\
DOIS IRMÃOS & TANIA TERESINHA DA SILVA & $56,33 \%$ \\
DOUTOR RICARDO & CATEA ROLANTE & $55,74 \%$ \\
\hline SERAFINA CORREIA & MARIA AMÉLIA GHELLER - MEIA & $54,25 \%$ \\
QUEVEDOS & NEUSA DOS SANTOS NICKEL & $53,53 \%$ \\
\hline CRISTAL & FABIA RICHTER & $53,00 \%$ \\
\hline ALEGRETE & CLENI PAZ & $52,30 \%$ \\
\hline
\end{tabular}




\begin{tabular}{lll}
\hline FAGUNDES VARELA & CLAUDIA MORECHI TOMÉ & $51,79 \%$ \\
\hline IBIAIARAS & IVETE LUCHEZI & $51,71 \%$ \\
\hline CAMARGO & ELIANI TRENTIN - NINA & $51,70 \%$ \\
\hline MUITOS CAPÕES & RITA DE CASSIA PEREIRA & $51,68 \%$ \\
\hline SANTA MARIA DO HERVAL & MARA SUSANA STOFFEL & $51,65 \%$ \\
FORTALEZA DOS VALOS & MARCIA FREDI & $50,86 \%$ \\
\hline SÃO PEDRO DA SERRA & ISABEL JONER CORNÉLIUS & $50,69 \%$ \\
TURUÇU & SELMIRA FEHRENBACH & $49,62 \%$ \\
\hline SÃO JOSÉ DO NORTE & FABIANY ROGNI ZOIG & $49,26 \%$ \\
\hline MAXIMILIANO DE ALMEIDA & DIRLEI BERNADI DOS SANTOS & $42,42 \%$ \\
\hline SAPIRANGA & CORINHA BEATRIZ MOLLING & $41,30 \%$ \\
\hline SINIMBU & SANDRA BACKES & $39,46 \%$ \\
NOVO HAMBURGO & FATIMA DAUDT & $33,98 \%$ \\
\hline ESTÂNCIA VELHA & IVETE GRADE & $33,12 \%$ \\
\hline
\end{tabular}

Fonte: Elaboração das autoras, com base nos dados do TRE-RS.

Quanto às composições de perfis dessas prefeitas gaúchas eleitas em 2016, para o mandato 2017-2020, apresentam-se algumas características no Gráfico 2: Estado Civil, 3 Idade, 4 Escolaridade, 5 Cor/Raça, e, na Tabela 5, Profissão.

\section{Gráfico 2 - Estado civil}

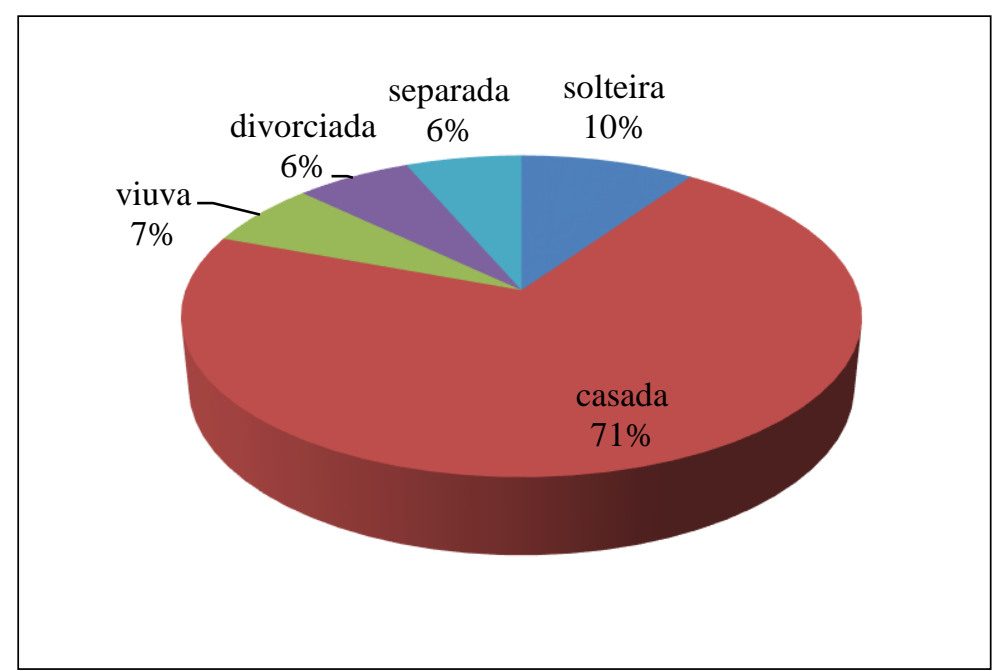

Fonte: Elaboração das autoras, com base nos dados do TRE-RS 


\section{Gráfico 3 - Idade}

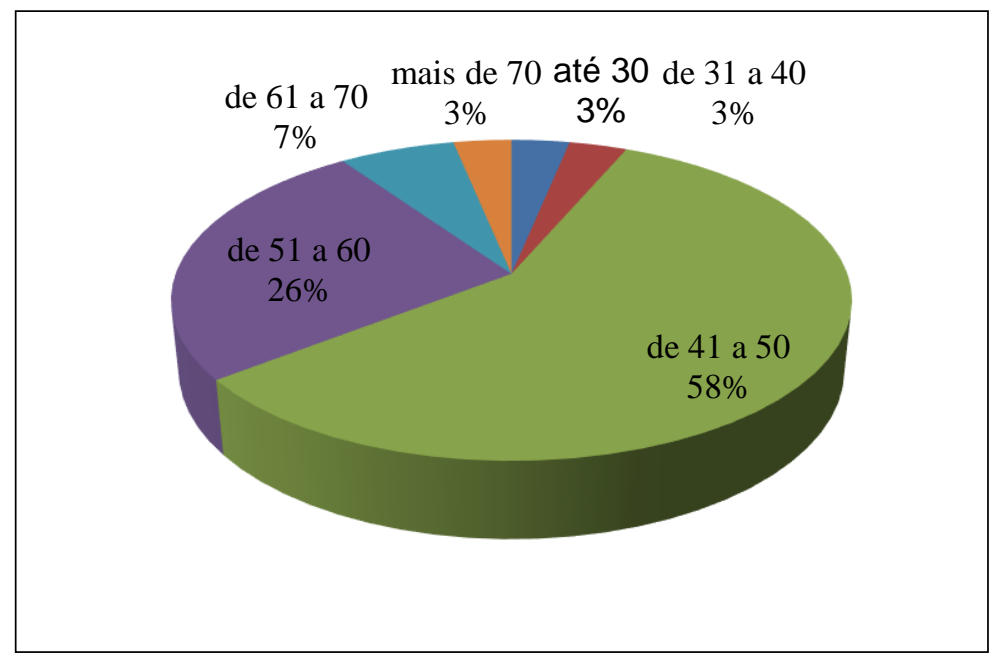

Fonte: Elaboração das autoras, com base nos dados do TRE-RS

O perfil predominante das prefeitas eleitas é o de serem casadas (71\%), com idades entre 41 e 50 anos (58\%), nível superior completo (71\%) e de cor branca (94\%). Este perfil demonstra algumas peculiaridades sobre as prefeitas.

Sobre o estado civil, Blay (2015), em seu estudo sobre as prefeitas, propõe-se a classificá-las, estabelecendo um critério intrinsecamente ligado às suas relações familiares de origem ou de matrimônio. A autora propõe a seguinte classificação: prefeita coronel, prefeita esposa e prefeita por iniciativa própria.

\section{Gráfico 4 - Escolaridade}

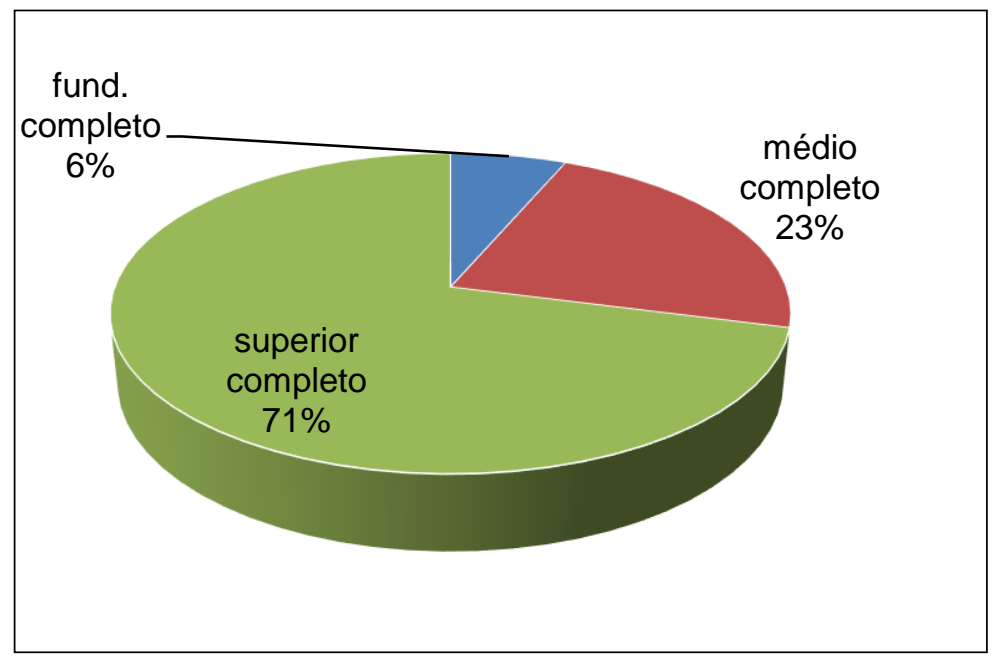

Fonte: Elaboração das autoras, com base nos dados do TRE-RS 


\section{Gráfico 5 - Cor / Raça}

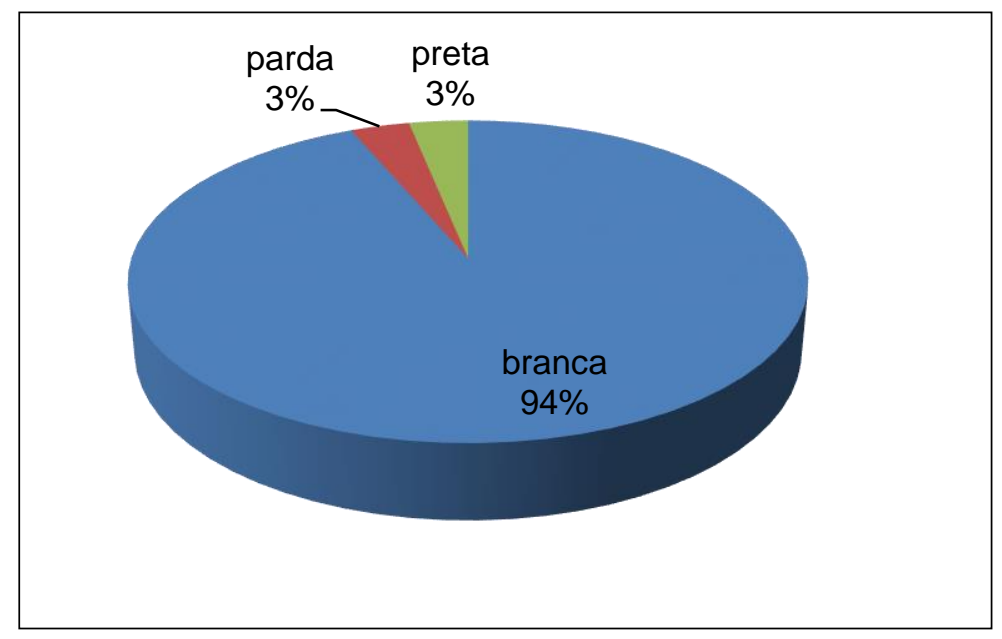

Fonte: Elaboração das autoras, com base nos dados do TRE-RS

Sobre a escolaridade, a maioria (71\%) possui curso superior completo, o que é um fato bastante positivo, se partir-se de um pressuposto de que possuir algum curso superior pode demonstrar melhor preparo para o enfrentamento das questões e resoluções de problemas na administração pública municipal.

Já sobre a cor/raça, a maioria é predominantemente branca, o que demonstra outra sub-representação nesse cenário. Ainda mais raro do que mulheres eleitas prefeitas, são mulheres não brancas eleitas prefeitas. O destaque aqui é para a prefeita de Dois Irmãos, Tania da Silva, eleita em 2012 e reeleita em 2016, a qual figura como a primeira mulher negra a ser eleita prefeita de um município no Rio Grande do Sul.

Sobre as profissões dessas prefeitas, apresentam-se as informações na Tabela 7. 
Tabela 7 - Profissão das prefeitas

\begin{tabular}{ll}
\hline PROFISSÃo & \\
\hline Prefeita & 5 \\
\hline Professora & 5 \\
\hline Servidora pública & 4 \\
\hline Comerciante & 3 \\
\hline Administradora & 1 \\
\hline Advogada & 1 \\
\hline Agricultora & 1 \\
\hline Aposentado & 1 \\
\hline Arquiteta & 1 \\
\hline Dona de casa & 1 \\
\hline Empresária & 1 \\
\hline Funcionária pública (cargo de comissão) & 1 \\
\hline Vereadora & 1 \\
\hline Não informou & 5 \\
\hline
\end{tabular}

Fonte: Elaboração das autoras, com base nos dados do TRE-RS.

\section{Considerações finais}

Ao observar as mudanças políticas e culturais, mesmo que superficialmente, é possível considerar, nas últimas décadas, uma tendência, ainda que pouco expressiva, de inserção das mulheres nas disputas eleitorais. A Lei 9504/97, cotidianamente conhecida como "Lei das Cotas", que estabelece hoje um percentual mínimo de 30\% de candidaturas femininas nas nominatas das coligações, parece ser um mecanismo afirmativo de inserção das mulheres na política. Embora ainda haja críticas sobre sua efetividade, é possível considerar que, mesmo que de forma lenta e gradual, esse instrumento legislativo passa a ser uma ação afirmativa para as mulheres.

Por outro lado, ao observar alguns dados quantitativos sobre a participação política feminina, num país com 5568 municípios e um estado com 487 municípios, que elegeram, em 2016, respectivamente, 637 e 31 prefeitas, ainda é possível encontrar indícios de mecanismos de dominação que, ainda hoje, mantém a baixa participação das mulheres nas instâncias representativas da política e do poder. O fato de a população, tanto brasileira como gaúcha, ser de maioria feminina (IBGE, 2010), e os cargos políticos serem majoritariamente ocupados por homens é um fenômeno que oferece muitas possibilidades de análise. Constatado esse fato, é necessário buscar as causas, os porquês desse 
entendimento, e quais as formas de superar essa visão de dominação. Embora este estudo tenha destacado esforços no sentido de identificar de forma apenas descritiva o número de prefeitas, os municípios que as elegeram e suas características, bem como o perfil das prefeitas eleitas, ele apresenta relevância no sentido de se entender o fenômeno das relações de gênero na política, na administração pública e na sociedade. Assim, coloca-se como um passo na percepção da realidade de mulheres nas suas relações sociais, sejam em organizações públicas ou privadas.

A cultura patriarcal impõe desvantagens às mulheres nos processos políticoeleitorais, e, para favorecer o envolvimento feminino nas ações partidárias e eleitorais, fazem-se necessárias mudanças sociais, culturais, históricas e até mesmo econômicas - no sentido de um real apoio financeiro de partidos às candidaturas femininas. A partir das mudanças, alguns importantes pontos, tanto nos aspectos públicos quanto privados das mulheres, podem ser trabalhados com vistas à atuação política feminina: a formação política feminina, o apoio familiar com vistas à disponibilidade de tempo para essas ações, a disponibilidade de espaços de discussão nos partidos, baseando-se em uma lógica de atuação política independente, que permita a igualdade de representações de gêneros entre os candidatos.

Nesse sentido, aprofundar o debate sobre a sub-representação das mulheres nos espaços de poder e conhecer os perfis e realidades das mulheres que exercem poder em qualquer nível da esfera pública é uma das formas de entender as mulheres como seres políticos e romper com o tradicionalismo que prioriza os homens no processo eleitoral.

Como possibilidade de estudos futuros, sugere-se a investigação com um olhar aprofundado em relação a essas mulheres que se tornaram prefeitas, buscando identificar as suas vivências, entender as suas particularidades, seus desafios, aprendizados e superações nessa carreira tradicionalmente ocupada por homens, mas que gradativamente torna-se também um espaço onde as mulheres dedicam sua vida e carreira. Esse é o desafio lançado neste estudo. Embora não seja tarefa simples, é importante fazer-se cruzar as fronteiras disciplinares, percorrer técnicas e métodos que possibilitem um olhar multi e interdisciplinar, para entendermos mais esses desafios das carreiras femininas, especialmente na administração pública. Por meio de conhecimento, contribui-se para a 
mudança da realidade. Eis o que se propõe ao investigar e sistematizar o conhecimento, mesmo que de forma descritiva, do perfil das prefeitas gaúchas.

\section{Referências}

ALVES, J. Paradoxos da participação política da mulher no Brasil. 2007. 15fl. Disponível em <http://www.prt18.mpt.gov.br/eventos/2007/mulher/anais/artigos/ jose_eustaquio.pdf>. Acesso em: $10 \mathrm{fev} .2017$.

ARAÚJO, C. Gênero e acesso ao poder legislativo no Brasil: as cotas entre as instituições e a cultura. Revista Brasileira de Ciência Política, Brasília, n. 2, p. 23-59, jul./dez. 2009.

ARAÚJO, C.; BORGES, D. O "gênero", os "elegíveis" e os "não-elegíveis": uma análise das Candidaturas para a Câmara Federal em 2010. In: ALVES, José Eustáquio Diniz; PINTO, Céli Regina Jardim; JORDÃO, Fátima (Orgs.). Mulheres nas eleições 2010. São Paulo: ABCP/ SPPM, 2012. p. 337-387

ALVES; PINTO; JORDÃO.

ALVES, José Eustáquio Diniz; PINTO, Céli Regina Jardim; JORDÃO, Fátima. Mulheres nas eleições 2010. São Paulo: ABCP/SPPM, 2012. p. 337-385.

BLAY, E. A. As prefeitas: a participação política da mulher no Brasil. São Paulo: Humanitas: CERU/FFLCH/USP, 2015.

. Mulher e igualdade: cidadania e gênero. Social Democracia Brasileira, Brasília, v. 1, n. 2, p. 58-63, mar. 2002.

BRABO, T. Gênero e poder local: eleições municipais do ano 2000 em Marília (SP). 2003. Tese (Doutorado em Sociologia) - Universidade de São Paulo, São Paulo, 2003.

CUNHA, A; SPANHOL, C. Liderança Feminina: Características e Importância à Identidade da Mulher. Saber Humano - Ano 4, n. 5, 2014.

FLETCHER, J. Gender perspectives on work and personal life research, 2006. Disponível em: <www.popcenter.umd.edu/events/nichd/papers/fletcher.pdf>. Acesso em: 20 out. 2016.

FUNDAÇÃO DE ECONOMIA E ESTATÍ́STICA. FEE. Perfil Socioeconômico RS - Municípios. 2017. $<$ http://www.fee.rs.gov.br>. Acesso em: 10 jan. 2017.

GOMES, J. Direito Eleitoral. 10. ed. São Paulo: Atlas, 2014. 
GROSSI, M; MIGUEL, S. Transformando a Diferença: As mulheres na Política. Estudos Feministas. Ano 9, 20 semestre 2001, p. 167-206.

INSTITUTO BRASILEIRO DE ADMINISTRAÇÃO MUNICIPAL. IBAM. Perfil dos Prefeitos Eleitos. 2016. Disponível em http: <//www.ibam.org.br/estudos>. Acesso em: 12 jan. 2017.

LOVENDUSKI, J.; NORRIS, P. Gender and Party Politics. London: Sage, 1993.

MIGUEL, L.; BIROLI, F. Práticas de gênero e carreiras políticas: vertentes explicativas. Revista Estudos Feministas, Florianópolis, v. 18, n. 3, p. 653-679, set., 2010.

PINTO, C. Paradoxos da participação política da mulher no Brasil. Revista USP, São Paulo, n. 49, p. 98-112, mar./maio 2001.

SACCHET, T; SPECK, B. Dinheiro e sexo na política brasileira: financiamento de campanha e desempenho eleitoral em cargos legislativos. 2010. In: ALVES; PINTO; JORDÃO. Mulheres nas eleições 2010. São Paulo: ABCP/SPPM, 2012, p. 417-452.

SOUZA, P; SIQUEIRA, E; BINOTTO, E. Liderança Feminina na Gestão Pública: um estudo de caso da Universidade do Estado do Rio Grande do Norte. 2011. Disponível em:

<http://www.abepro.org.br/biblioteca/enegep 2011TNSTP14189318429.pdf>. Acesso em: 21 out. 2016.

TRIBUNAL REGIONAL ELEITORAL DO RIO GRANDE DO SUL. TRE-RS. Eleições 2012: Divulgação dos Resultados. Disponível em: <http://www.tre-rs.jus.br/eleicoes/2012/1turno/RS87483>. Acesso em: 10 jan. 2017.

TRIBUNAL SUPERIOR ELEITORAL. TSE. Disponível em: <http://www.tse.jus.br/>. Acesso em: 20 jan. 2017.

VAZ, G. A participação da mulher na política brasileira: a lei de cotas. Monografia. $65 f$. (Especialização em Processo Legislativo) - Centro de Formação, Treinamento e Aperfeiçoamento, Câmara dos Deputados, Brasília, 2008. 